\title{
Design of Intelligent Power Service Business Model for Industrial Parks
}

\author{
Ming Zeng ${ }^{1}$, Mingzhu Li ${ }^{1}$, Yingxin Liu $^{1}$, Yuqing Wang ${ }^{1}$, Chenjun Sun ${ }^{2}$ a \\ ${ }^{1}$ School of Economics and Management, North China Electric Power University, Beijing 102206, \\ China;
}

${ }^{2}$ State Grid Hebei Electric Power Co., Ltd., Hebei 050000, China.

a532300376@qq.com

Keywords: Intelligent power service, business model, industrial parks.

\begin{abstract}
The core of intelligent power service for industrial parks is to provide users with better power conditions without increasing usage costs of users. Intelligent value-added service is not only an extension of power services, but also a historical opportunity for the transformation of power services into smart services under the conditions of smart grids. This paper proposes four phases of intelligent power service for industrial parks according to the time scale and the development degree of electricity market, and details the business model in stages.
\end{abstract}

\section{Current Period: Business Model Based on Orderly Use of Electricity by Users}

In the case of grids with insufficient peak load regulation capacity or equipment failures, users of industrial parks need to be managed in an orderly manner. The fair and orderly power consumption model uses weeks as the unit of time. According to the user's interaction ability, the user's orderly power sequencing is optimized and the user's orderly power consumption schedule is formulated in advance. To ensure the safety of grids at the cost of minimal loss of load.

The organizer of the orderly electricity plan needs to provide users with value-added information service in the process of orderly electricity use. The organizer needs to establish an information sharing platform, and promptly inform users of their orderly use of electricity plans so that users can prepare in advance to make the information transparent and transparent. After the completion of the weekly electricity plan, the organizer needs to use the information sharing platform to publish the orderly electricity plan in a timely manner. The open and transparent information can ensure the fairness of orderly electricity consumption planning, while leaving sufficient preparation time for users to minimize losses. On the day before the implementation of the plan, the organizer of the orderly electricity plan should remind users of the orderly electricity plan of the next day. If the grid operation department needs the industrial park to implement the orderly electricity plan, the organizer of the orderly electricity plan shall promptly notify the users who need to adjust the power load and take prompt response measures.

The value-added information service provision method of intelligent power service for industrial parks is shown in figure 1.

In the current era, information is one of the most precious resources. As the executor of the orderly electricity plan at this stage, grid companies can obtain a large amount of users' power consumption information and grasp users' load characteristics and power consumption habits during the implementation of the orderly electricity plan. Grid companies can use the marketing platform to achieve smooth communication with users, and provide users with high-quality services free of charge thanks to their abundant power technology service capabilities. Grid companies can utilize users' load information learned during the implementation of the orderly electricity plan to provide users with more targeted and close-to-user value-added services. It is worth noticing that, unlike general commodities, electric energy has social properties. Grid companies provide users with value-added services to ensure that users can use electricity with a better user experience. This is also a full expression of the social responsibility. 


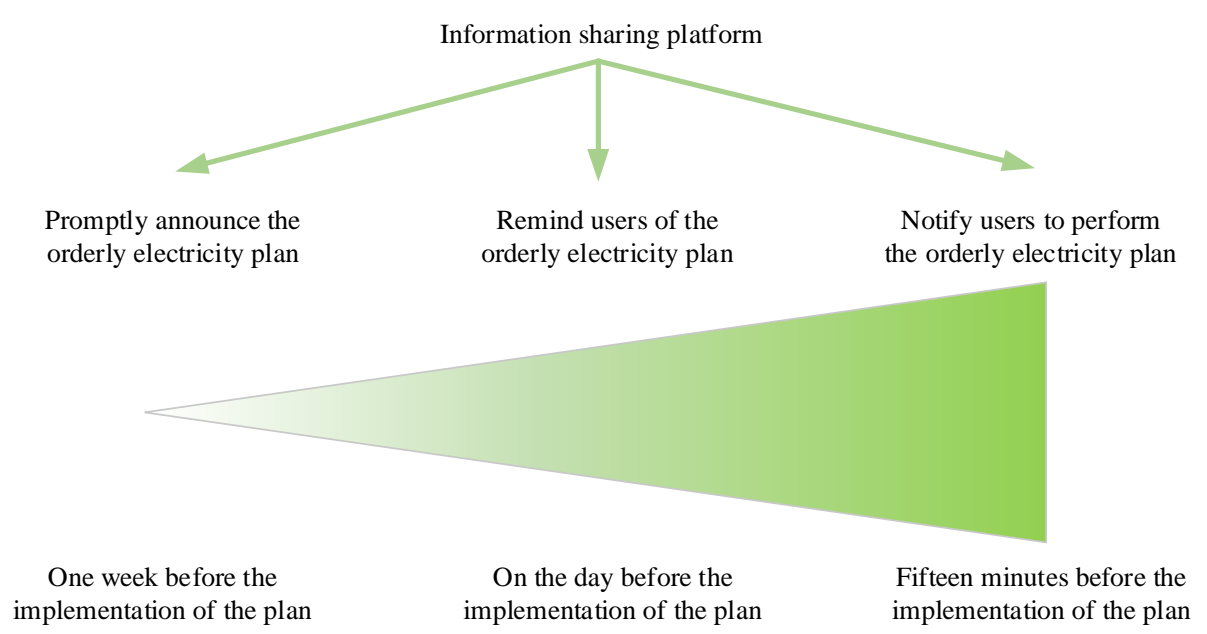

Figure 1. The value-added information service provision method of intelligent power service for

\subsection{Value-Added Services.}

industrial parks

Provide users with more reasonable orderly power plans.

Establish an orderly power information publishing platform and timely release relevant information.

Provide energy efficiency diagnostic service for power users, diagnosis high energy consumption behaviors, and propose reasonable energy saving plans.

\subsection{Policy Conditions.}

The government formulates the "orderly electricity usage plan." each year. Grid companies are responsible for the specific implementation of the orderly electricity plan. Users who have signed an orderly electricity agreement with grid companies must strictly implement the relevant ordered electricity orders issued by grid companies.

\section{Recent Period: Business Model Based on Energy Efficiency Management}

In recent years, energy efficiency represented by energy intensity has been significantly improved worldwide. The improvement of energy efficiency has a series of advantages such as reducing the country's dependence on energy imports, maintaining energy security, reducing new energy development costs, reducing the pollution caused by the use of energy in the region, and improving the competitiveness of enterprises. As the largest developing country in the world, China has attracted attention to of all countries in the world for not only because of the speed of economic development but also because of its rapidly growing total energy consumption and total greenhouse gas emission. Looking into the future, China still faces great challenges in dealing with energy consumption and low energy efficiency.

With the rapid economic development and the gradual advancement of industrialization, China has also shown a rapid growth state of energy consumption, and the energy supply and demand situation has become increasingly tight. During the "Eleventh Five-Year Plan" period, structural energy-saving had been achieved through the implementation of measures to eliminate backward production capacity, develop differential pricing, and control the growth of high-energy-consuming industries. Through the implementation of thousands of corporate actions, ten key energy-saving projects, 3515 energy-saving actions and other programs, energy-saving technologies had been achieved. Through the above-mentioned efforts, the energy-saving target of $20 \%$ reduction in energy consumption per unit of GDP had been successfully achieved, and energy efficiency had improved significantly.

However, energy-saving measures and policies only based on structural adjustment and energy-saving technologies are insufficient to meet the needs. The concept of energy efficiency management emerged as the times require. It is necessary to establish a set of scientific and rational, wide-ranging energy efficiency management and policy implementation systems to ensure the 
coordinated development of the current energy environment and economy in the medium to long term.

\section{Mid-Term: Business Model Based on Energy Agency}

This article proposes an agent operating model for smart industrial parks in the context of energy agency. Under this model, agents, as emerging market players, negotiate power purchases on behalf of users and use the complementary benefits of the load curves to obtain a more profitable agent load curve for power plants in order to get more favorable electricity prices in energy agency.

In the operation process, agents not only provide users with electricity purchasing services, but also provide corresponding value-added services to provide users with more convenience. The value-added services that agents need to provide in all aspects of operations are shown in figure 2.

Full-time value-added services in agency model
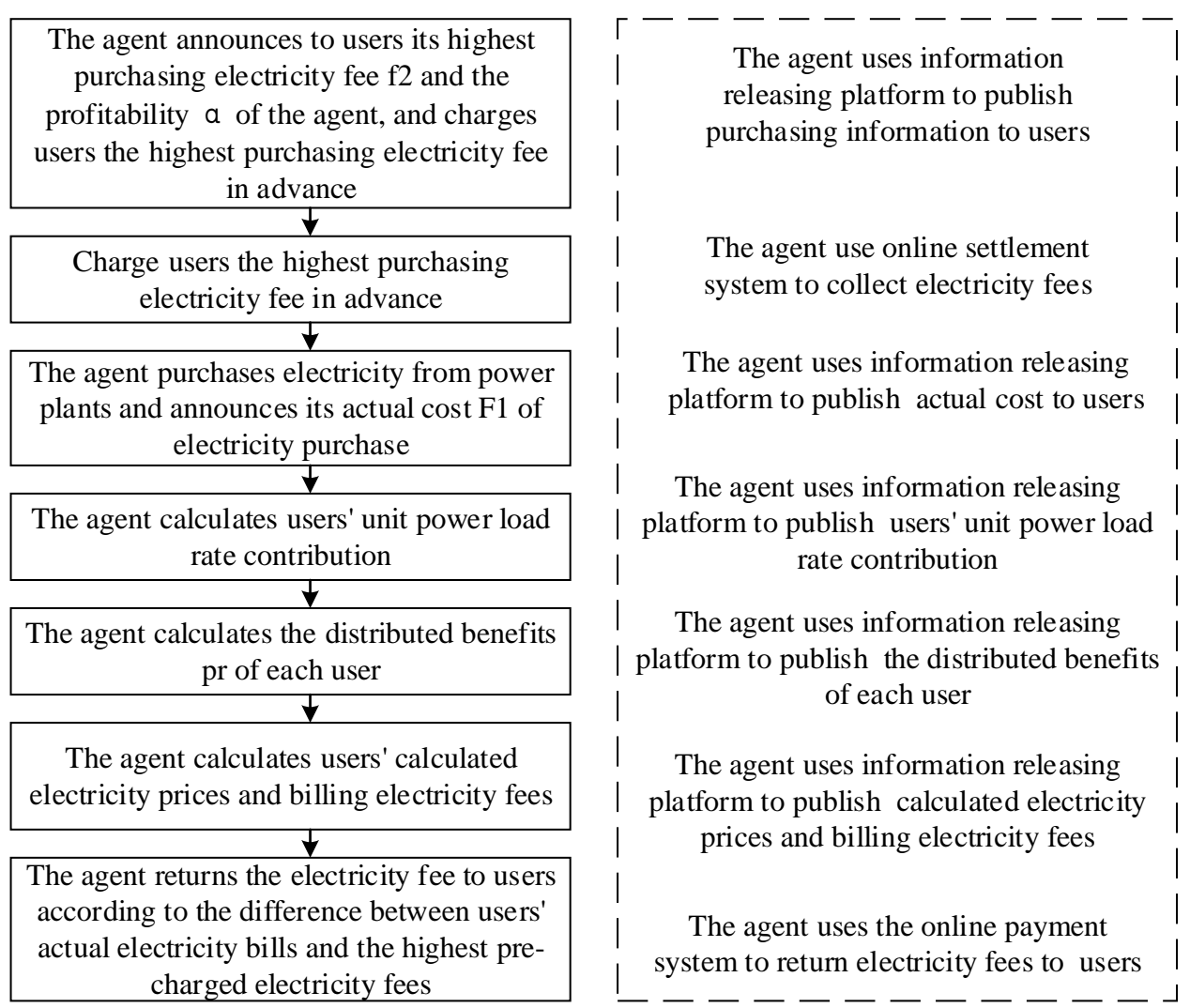

Figure 2. Value-added services that agents need to provide in all aspects of operations

As shown in the above figure, agents need to provide value-added services at all stages of operations, complete information disclosure, and collect and transfer fees.

Agents who involve in the sale side market need to fully understand users' power consumption information. Thanks to the grasp of users' power curve characteristics, agents can accurately assess users' electricity purchasing cost, understand users' willingness to purchase electricity, accurately assess the profitability of power sale market, and provide corresponding value-added services according to the needs of users, attracting users to participate in agent purchasing electricity. If the power grid company has accumulated a large amount of user load characteristic information during the implementation of the orderly electricity plan, the power grid company will have natural advantages in participating in the power sale market as an agent.

\subsection{Value-Added Services.}

Provide credit rating assessment for banks.

Agents hold users' power consumption information and can provide assessment support of normal production status for banks' credit audit departments. 


\subsection{Policy Conditions.}

Energy agency is allowed to open. Agents are allowed to sign bilateral electricity purchasing agreements with power plants directly.

\section{Long-Term: Business Model Based On Mature Electricity Market}

With the deepening of electricity market reform, China will further open medium and long-term contract market, day-ahead market, real-time market, reserve market, the capacity market, auxiliary service market, and electricity finance market and other types of electricity market on the basis of the energy agency contract market to form a diversified market structure in which different markets promote, complement and coordinate with each other.

Under this condition, market managers can provide users with more abundant value-added services. According to the characteristics, regulations and requirements of different markets, market managers can provide users with a variety of power service packages in the most concise manner. For example, market managers can provide users with online transaction services. Using menu-based selection methods, market managers provide online store services to facilitate users to purchase corresponding services directly on the internet according to their own needs. Users can also easily and quickly implement online electricity payment and service shop fee payment through the online payment platform, without having to go to the business office to wait for processing. In addition, market managers can publish current and historical power load status of users through the network service platform, analyze the user load characteristics, provide the distribution situation of user load during the peak-valley period, evaluate users' power efficiency, and provide information support for user decisions.

Under the new open electricity market pattern, power service providers should spare no efforts to provide users with the most convenient and most comprehensive value-added services.

\subsection{Value-Added Services.}

Provide users with more diversified and user-friendly electricity packages.

Grid companies analyze users' electricity consumption curve to provide users with reasonable suggestions for reducing the cost of electricity and provide users with reasonable package options.

Provide electric fee prepayment financial service with a certain rate of return.

By attracting prepaid electricity bills from users in industrial parks, grid companies will use pre-paid fees to set up funds, gain profits through financial market operations, and return some of their profits to pre-paid users.

Provide construction and operation management services for distributed power in industrial parks.

Distributed power supply companies, energy conservation service companies and other market players use the space resources of industrial parks to install distributed power for users, such as photovoltaic and wind turbines. Distributed power generates electricity for users, and users pay service fees to manufacturers and energy-saving service companies. Users' surplus power is sent back to the grid. The revenue of this part of the power is owned by the manufacturers and the energy-saving service companies.

\subsection{Policy Conditions.}

At this stage, there is a need for a sound system of electricity market institutions, a flexible and rapid electricity price transmission mechanism, and an easy financial policy to promote competition in the electricity market.

\section{Conclusion}

Power users not only need low-cost, high-reliability power services, but also want to enjoy customized, personalized service content. At the same time, the customers also hope to achieve convenient interaction with the power grid companies through the communication system, have detailed understanding of their own electricity consumption behaviors and specific methods of using electricity, realize transparent services, and facilitate product selection, payment settlement, 
information inquiry, malfunction service, electric vehicle charge and discharge booking service and other services. This paper designs business models for intelligent power service for industrial parks, sorts out the required policy conditions, and provides electric service providers with improve direction and development path.

\section{Acknowledgments}

The paper is supported by the Science and Technology Program of SGCC (Implementation plan and support system of constructing power service platform by SGCC under the new policy environment).

\section{References}

[1]. Shang C, Tina Y, Yu J, et al. Application of Intelligent Power Service System in Power Marketing[C]// International Conference on Education, Management, Computer and Society. 2017.

[2]. Wu R Z, He Y, Wang X Y. Scheme on bilateral interaction information service implement towards intelligent power utilization[C]// China International Conference on Electricity Distribution. IEEE, 2013:1-4.

[3]. Dai Q H, Zhang R H. The Design of Intelligent Service System in the Power Supply Enterprises Based on SOA [J]. Applied Mechanics \& Materials, 2013, 411-414:2027-2030.

[4]. Wang J Y, Si-Wei L I. Design of Smart Home Energy Efficiency Management System based on the Intelligent Interactive Power Service Platform [J]. Electric Power Information Technology, 2012.

[5]. Song R P, Yu-Xin W U. Applied Research on Intelligent Power Consumption Service System [J]. Electric Power Information Technology, 2012.

[6]. Collins B A, Macnichol E F. Construction of Power Customer Intelligent Service System Based on Provincial Level Centralization Mode [J]. Inner Mongolia Electric Power, 2011, 167(2):437-444.

[7]. Chen H, Zhan Y, Zhang S F. Design and Realization of Power Intelligent Service System [J]. Journal of Hebei University, 2010. 